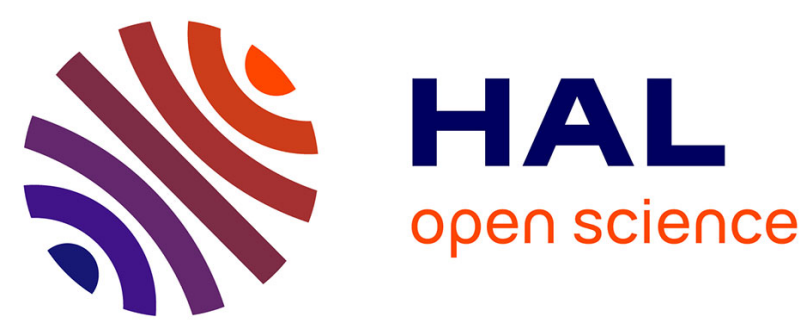

\title{
Impact of untreated urban waste on the prevalence and antibiotic resistance profiles of human opportunistic pathogens in agricultural soils from Burkina Faso
}

Benjamin Youenou, Edmond Hien, Amélie Deredjian, Elisabeth Brothier, Sabine Favre-Bonté, Sylvie Nazaret

\section{To cite this version:}

Benjamin Youenou, Edmond Hien, Amélie Deredjian, Elisabeth Brothier, Sabine Favre-Bonté, et al.. Impact of untreated urban waste on the prevalence and antibiotic resistance profiles of human opportunistic pathogens in agricultural soils from Burkina Faso. Environmental Science and Pollution Research, 2017, 10.1007/s11356-016-7699-5 . hal-02335533

\section{HAL Id: hal-02335533 \\ https://hal.science/hal-02335533}

Submitted on 29 Oct 2019

HAL is a multi-disciplinary open access archive for the deposit and dissemination of scientific research documents, whether they are published or not. The documents may come from teaching and research institutions in France or abroad, or from public or private research centers.
L'archive ouverte pluridisciplinaire HAL, est destinée au dépôt et à la diffusion de documents scientifiques de niveau recherche, publiés ou non, émanant des établissements d'enseignement et de recherche français ou étrangers, des laboratoires publics ou privés. 


\title{
Impact of untreated urban waste on the prevalence and antibiotic resistance profiles of human opportunistic pathogens in agricultural soils from Burkina Faso
}

\author{
Benjamin Youenou ${ }^{1}$ • Edmond Hien ${ }^{2}$ - Amélie Deredjian ${ }^{1}$ Elisabeth Brothier ${ }^{1}$. \\ Sabine Favre-Bonté ${ }^{1} \cdot$ Sylvie Nazaret $^{1}$ (D)
}

Received: 31 May 2016 / Accepted: 12 September 2016

(C) Springer-Verlag Berlin Heidelberg 2016

\begin{abstract}
This study examined the long-term effects of the landfill disposal of untreated urban waste for soil fertilization on the prevalence and antibiotic resistance profiles of various human opportunistic pathogens in soils from Burkina Faso. Samples were collected at three sites in the periphery of Ouagadougou during two campaigns in 2008 and 2011. At each site, amendment led to changes in physico-chemical characteristics as shown by the increase in $\mathrm{pH}, \mathrm{CEC}$, total C, total N, and metal contents. Similarly, the numbers of total heterotrophic bacteria were higher in the amended fields than in the control ones. No sanitation indicators, i.e., coliforms, Staphylococci, and Enterococci, were detected. Pseudomonas aeruginosa and Burkholderia cepacia complex (Bcc) were detected at a low level in one amended field. Stenotrophomonas maltophilia was detected from both campaigns at the three sites in the amended fields and only once in an unamended field. Diversity analysis showed some opportunistic pathogen isolates to be closely related to reference clinical strains responsible for nosocomial- or communityacquired infections in Northern countries. Antibiotic resistance tests showed that $P$. aeruginosa and Bcc isolates had a wild-type phenotype and that most $S$. maltophilia isolates had
\end{abstract}

Responsible editor: Robert Duran

Sylvie Nazaret

sylvie.nazaret@univ-lyon1.fr

1 Research Group on « Multi-résistance environnementale et efflux bactérien», UMR 5557 Ecologie Microbienne, CNRS, VetAgro Sup and Université Lyon 1, 43, Boulevard du 11 Novembre 1918, Villeurbanne Cedex, 69622 Villeurbanne, France

2 LMI IESOL, UMR Eco\&Sols, IRD-Université de Ouagadougou, UFR/SVT 03 BP 7021, Ouagadougou, Burkina Faso a multi-drug resistance profile with resistance to 7 to 15 antibiotics. Then we were able to show that amendment led to an increase of some human opportunistic pathogens including multi-drug resistant isolates. Although the application of untreated urban waste increases both soil organic matter content and therefore soil fertility, the consequences of this practice on human health should be considered.

Keywords Human opportunistic pathogen - Soil · Antibiotic resistance $\cdot$ Burkina Faso $\cdot$ Urban waste

\section{Introduction}

Soils on earth are extremely diverse and are characterized by an extreme heterogeneity of physical and chemical properties offering various microsites for microorganism colonization. Therefore, soils are one of the major reservoirs of prokaryotic diversity (Whitman et al. 1998). Human bacterial pathogens can be part of these indigenous soil microbial communities. Some of the species belonging to Clostridium (Clostridium perfringens, Clostridium tetani, Clostridium botulinum), Bacillus (Bacillus anthracis), Mycobacterium (Mycobacterium tuberculosis), or Burkholderia (Burkholderia pseudomallei) genera are considered typical soil inhabitants either because they or their close relatives were isolated from soil samples, i.e., B. pseudomallei, Bacillus cereus, and Mycobacterium bovis (Young et al. 2005; Kuske et al. 2006; Trung et al. 2011). Similarly, several emergent opportunistic pathogens were reported as abundant in soil and plant rhizospheres. Various species responsible for infections among cystic fibrosis patients (i.e., Burkholderia cenocepacia, Stenotrophomonas maltophilia, and species belonging to Pseudomonas genus) were frequently isolated from soil and root samples (Berg et al. 2005; Mendes et al. 2013). 
Some of these species (Hickey and Focht 1990; Vedler et al. 2004; Ali et al. 2010) were also frequently isolated from polluted sites such as hydrocarbon- or pesticide-contaminated soils. Pathogens can also be transient inhabitants of soil brought from exogenous sources. Agricultural practices such as irrigation with wastewater, fertilization with municipal waste, or animal-derived products (i.e., bovine manure, pig slurry, poultry droppings) can contribute to the dispersion of both chemical and biological contaminants in terrestrial environments.

Whereas evidence from the impact of toxicants as metals on microbial activity and soil fertility is well documented (Smith 2009; Singh et al. 2011), less is known about the direct or indirect impact of these practices on the dissemination and/ or selection of pathogens. Reports from the literature indicated that some pathogens such as Escherichia coli, Campylobacter jejuni, Yersinia enterolitica, and Listeria monocytogenes can enter the soil through the spread of sewage sludge, municipal solid waste (Garrec et al. 2003; Semenov et al. 2009), and organic waste of animal origin (Meng and Doyle 1997; Farzan et al. 2010). Despite a few reports on the presence of Pseudomonas aeruginosa in farmyard manures (Colinon et al. 2013; Deredjian et al. 2014), composted industrial waste (Kaszab et al. 2011), and wastewater treatment plants (Lavenir et al. 2007; Lee et al. 2008; Edrington et al. 2009), little data is available regarding the presence and behavior of opportunistic pathogens in water or solid waste used for agriculture practices in the environment.

Human opportunistic bacteria are known for their antibiotic resistance properties which are traditionally attributed to high intrinsic resistance and the ability to acquire novel resistance genes by horizontal gene transfer (Sanchez et al. 2009; Alvarez-Ortega et al. 2011). The use of antibiotics and antiseptics contributes greatly to the increasing level and subsequent spread of resistance among these species in hospital settings (Canton and Morosini 2011; Livermore 2012). Antibiotic resistance in the environment is also directly affected by the release of antibiotic resistant bacteria and antibiotic residues via waste from human or animals receiving therapeutic antibiotics (Baquero et al. 2008, Jechalke et al. 2014). Manure and biosolids spreading in agricultural lands might be a source of antibiotic resistant bacteria when applied as biofertilizers to farmland as they are known to contain microbial pathogens (Zhu et al. 2013; Su et al. 2015). Consequently, agriculture practices might contribute to the distribution of opportunistic bacteria as well as their resistance properties.

Data from the literature mainly focuses on the distribution of opportunistic pathogens in northern countries as they are of concern near hospitals due to their implication in nosocomial infections and in the colonization of cystic fibrosis patients. Little data is available on the prevalence of pathogens including opportunistic ones in African countries in soils under different pedo-climatic context. Similarly, due to the increase in mineral fertilizer prices, the spreading of municipal waste materials is a common practice among farmers of developing countries in sub-Saharan African areas and especially in urban and peri-urban agriculture (Eaton and Hilhorst 2003; Afon 2007). However, in these areas, waste is often used fields without selection or pre-treatment (Kaboré et al. 2010).

The main objective of this study was to examine the longterm effects of a common agricultural practice, i.e., landfill disposal of untreated urban waste for soil fertilization, on the prevalence of various human opportunistic pathogens in subSaharan soils from Burkina Faso with regard to the impact on soil physico-chemical properties. To achieve this, amended and unamended soil samples from three agricultural sites in the periphery of Ouagadougou were sampled during two campaigns in 2008 and 2011. The abundance of culturable bacteria belonging to $P$. aeruginosa, $S$. maltophilia and Burkholderia cepacia complex (Bcc) was compared to that of the sanitation indicator bacteria to reveal the impact of exogenous sources on pathogen prevalence. Then within each opportunistic species, both a phylogenetic analysis based on the sequencing of genetic markers and antibiotic resistance profiles were performed to compare African soil isolates to reference strains from international collections of Northern countries.

\section{Material and methods}

\section{Field sites and sampling}

The study was conducted on three agricultural sites (Tabtenga, Toubwéogo, and Zagtouli) in the periphery of Ouagadougou, Burkina Faso. At each site, local farmers grow sorghum in fields modified every year with untreated solid urban waste (UW) to restore soil fertility. These fertilizers are made of 50$60 \%$ organic household waste (vegetables), as well as paper, glass, plastic, scrap iron, cans, and some contain hospital waste ( 5 to $20 \%$ of the amendment). The used amount of fertilizers is 20 to $30 \mathrm{t} \mathrm{ha}^{-1}$ year $^{-1}$. To evaluate the benefits of soil amendment on agronomic properties and crop production, one nearby field is kept unamended (control field). These sites allow the long-term assessment of the effects of amendment as these ferti individual sites have been used as landfills for between 8 and 20 years. All soils are petroplinthic leptosol (FAO-IUSS-ISRIC 2006). Soil physico-chemical characteristics were measured by the Laboratory of Soil Analysis (INRA Arras, France) using standard methods.

At each site, sampling was carried out at the surface layer $(0-5 \mathrm{~cm})$ in an amended field and a control one. In June 2008 (6 months after the crop harvest and about 1 month after amendment), soil samples from each field were collected as follows: three transects per field were done and 10 samples taken every $2 \mathrm{~m}$ along a $20-\mathrm{m}$ transect were mixed to make a 
composite sample. The 18 samples ( 3 transects $\times 2$ treatments $\times 3$ sites) were placed in plastic bags and taken to the laboratory, where they were immediately sieved (2-mm mesh size), homogenized, and used for bacterial counts. A second campaign was conducted in February 2011 (3 months after the crop harvest and about 8 months after amendment) on the Tabtenga site. Five samples from one transect were taken from the control field and 25 samples from five transects from the amended field. Each sample is a composite of sub-samples taken every $2 \mathrm{~m}$ pooled by two along a $20-\mathrm{m}$ transect. The 30 samples were treated as mentioned above.

\section{Enumeration of TCH, sanitation indicators, and human opportunistic pathogens}

Total bacteria were extracted by blending $5 \mathrm{~g}$ of soil samples with $50 \mathrm{ml}$ of a $0.8 \%(w: v)$ sterile $\mathrm{NaCl}$ solution for $90 \mathrm{~s}$ in a Waring blender (Eberbach Corporation, MI, USA). The homogeneous soil suspension was serially diluted tenfold in sterile saline solution, and $100 \mu \mathrm{l}$ of appropriate dilutions were spread on the various media. All agars used in this study were purchased from Oxoid (Dardilly, France).

The total culturable heterotrophs $(\mathrm{TCH})$ were enumerated on a tenfold diluted Tryptic Soy Agar medium (TSA1/10). Enumeration of coliforms was carried out on TTC Tergitol 7 media. For Staphylococci and Enterococci recovery, Chapman and Slanetz media were used, respectively.

Regarding opportunistic pathogens, the VIA (vancomycin, imipenem, amphotericin B) selective agar medium was used to detect and isolate S. maltophilia. Dark green colonies with a blue halo morphotype were considered to be $S$. maltophilia and counted according to the procedure previously described (Pinot et al. 2011). P. aeruginosa isolation was performed using the Cetrimide Agar Base (CAB) medium (Oxoïd) supplemented with nalidixic acid $\left(15 \mathrm{mg}^{-1}\right)$. Enrichment assays were performed by transferring $2 \mathrm{~g}$ of soil into $20 \mathrm{ml}$ of a salt solution supplemented with acetamide, as described previously (Green et al. 1974). Inoculated enrichment broths were incubated for 3 days at $28{ }^{\circ} \mathrm{C}$ with shaking at $180 \mathrm{rpm}$. All the greenish and yellowish fluorescent colonies were picked from the plates for further identification as described in Lavenir et al. (2007) by targeting ecfX. Bcc were enumerated on two selective media: trypan blue tetracycline agar (TB-T) (Hagedorn et al. 1987) and B. cepacia selective agar (BCSA) (Henry et al. 1997). Colonies were confirmed as belonging to the $\mathrm{Bcc}$ as described in Mahenthiralingam et al. (2000) by targeting recA.

Cycloheximide $\left(200 \mathrm{mg} \mathrm{l}^{-1}\right)$ was added in all media to impair the growth of fungi. Three plates were inoculated per dilution. Bacterial colonies were counted after 5 days of incubation at $28{ }^{\circ} \mathrm{C}$ for TSA1/10 plates and after 24 to $48 \mathrm{~h}$ of incubation at $37^{\circ} \mathrm{C}$ for TTC tergitol 7, Slanetz, and Chapman plates. Plates were incubated at $28{ }^{\circ} \mathrm{C}$ for up to $48 \mathrm{~h}$ for S. maltophilia, at 28 and $37{ }^{\circ} \mathrm{C}$ for up to $72 \mathrm{~h}$ for P. aeruginosa, and at $28^{\circ} \mathrm{C}$ for up to 4 days for Bcc.

\section{Sanitation indicator identification and diversity of human opportunistic pathogens}

Bacterial DNA was extracted according to Pitcher et al. (1989). To ensure that the target organisms from selective media used for sanitation indicator enumeration were not misidentified, we recorded the number of bacteria in each morphology type and five to ten representatives of each recorded morphology type were selected for further identification based on 16S ribosomal DNA (rDNA) sequencing. 16S ribosomal RNA (rRNA) gene was amplified using the Taq DNA polymerase (MP Biomedicals, CA, USA), with $0.2 \mu \mathrm{M}$ of $8 \mathrm{~F}$ and $1492 \mathrm{R}$ primers in a $50 \mu \mathrm{L}$ reaction (Weisburg et al. 1991). Sequencing was performed on the 16S rRNA gene PCR fragment using primers 16S-515F, 16S-906F, and 16S-907R (Weisburg et al. 1991). Sequencing was performed by Biofidal (Villeurbanne, France). Identification to the species level was performed by comparison with the Ribosomal Database Project database (http://rdp.cme.msu.edu/) and by using Blast (http://blast.ncbi.nlm.nih.gov/Blast.cgi). The sequences of the identified bacterial isolates were deposited in the GenBank nucleotide sequence database under Accession Numbers KX146470 to KX146483.

Intraspecies diversity among $21 \mathrm{~S}$. maltophilia isolates was evaluated using partial gyrB gene sequencing as previously described (Yamamoto and Harayama 1998). Additional sequences from previously studied strains in Adamek et al. (2011) and from sequenced genomes (K279, R551-3, RR10, EPM1, SKA14, SO28, PML168, AU12-09, AB55555, D457, JV3) were retrieved from the GenBank database and included in the analysis.

The diversity of $38 P$. aeruginosa isolates was assessed by the sequencing of the ecf $\mathrm{X}$ marker as previously described (Lavenir et al. 2007). Fifteen sequences retrieved either from the whole genome of P. aeruginosa strains (PAO1, PA1, PA7, PA14, MTB-1, B136-33, PA96, YL84, SCV20265, LES431, DK2, c7447m, NCGM2.S1) or from uncultured environmental bacteria (riv1, lag2) were added.

The diversity analysis of 24 isolates from the Bcc was evaluated by analysis of the phylogeny obtained from the $r e c \mathrm{~A}$ sequences. Sequencing and analysis of a $955 \mathrm{bp}$ of the $r e c \mathrm{~A}$ gene was performed using the $\mathrm{BCR} 1$ and $\mathrm{BCR} 2$ primers (Mahenthiralingam et al. 2000). Other recA sequences from representative species belonging to the Bcc were obtained from the EMBL database and added in the recA phylogeny analysis. 


\section{Antibiotic resistance test}

The in vitro antimicrobial resistances of the isolates were routinely determined using the Vitek®2 system with a card (NO93) dedicated to non-fermenting Gram negative bacteria (Biomérieux, Marcy l'Etoile, France) according to manufacturer instructions. Minimal inhibitory concentrations of 18 antibiotics [ticarcillin (TIC 16, 32, $64 \mu \mathrm{g} / \mathrm{ml}$ ), ticarcillin/ clavulanic acid (TIM 8/2, 32/2, 64/2 $\mu \mathrm{g} / \mathrm{ml}$ ), piperacillin (PIP 4, 16, $64 \mu \mathrm{g} / \mathrm{ml}$ ), piperacillin/tazobactam (TZP 4/4, 16/ 4, 128/4 $\mu \mathrm{g} / \mathrm{ml}$ ), ceftazidim (CAZ 1, 2, 8, $32 \mu \mathrm{g} / \mathrm{ml}$ ), cefepim (FEP 2, 8, 16, $32 \mu \mathrm{g} / \mathrm{ml}$ ), aztreonam (ATM 2, 8, $32 \mu \mathrm{g} / \mathrm{ml}$ ), imipenem (IPM 2, 4, $16 \mu \mathrm{g} / \mathrm{ml}$ ), meropenem (MEM 0.5, 4, $16 \mu \mathrm{g} / \mathrm{ml}$ ), amikacin (AMK 8, 16, $64 \mu \mathrm{g} / \mathrm{ml}$ ), gentamicin (GEN 4, 16, $32 \mu \mathrm{g} / \mathrm{ml}$ ), isepamicin (ISP 4, 8, $32 \mu \mathrm{g} / \mathrm{ml}$ ), tobramicin (TOB 8, 16, $64 \mu \mathrm{g} / \mathrm{ml}$ ), ciprofloxacin (CIP 0.5, 2, $4 \mu \mathrm{g} / \mathrm{ml}$ ), pefloxacin (PEF 0.5, 2, $8 \mu \mathrm{g} / \mathrm{ml}$ ), colistin (CS 4, 16, $32 \mu \mathrm{g} / \mathrm{ml}$ ), minocyclin (MIN 2, 4, $8 \mu \mathrm{g} / \mathrm{ml}$ ), and trimethoprim/sulfamethoxazole (SXT 0.5/9.5, 2/38, 16/ $304 \mu \mathrm{g} / \mathrm{ml})$ ] were determined. MIC results provided by the Vitek®2 system were analyzed by the AESTM (Advanced Expert System) software incorporated in this system. Interpretations were established following the recommendations of the antibiogram committee of the French Society of Microbiology, (http://www.sfm-microbiologie.org).

\section{Statistical analysis}

Significant differences in bacterial numbers between soil samples were determined using $R$ with Student's $t$ test.

The nucleotide sequences obtained in this study and gene sequences previously reported and available in the GenBank database were aligned, and a phylogenetic tree was constructed using the Seaview 4.2 software (Gouy et al. 2010; pbil, Lyon, France). Multiple nucleotide sequence alignment was performed using the MUSCLE alignment algorithm (Edgar 2004). Multiple alignments were then cleaned with Gblocks (Talavera and Castresana 2007). The pairwise evolutionary distances were calculated using the Kimura2-parameter model. A phylogenetic tree was constructed using the neighborjoining (bioNJ) method with 1000 replicates using bootstrap.

\section{Results}

\section{Impact of amendment on soil characteristics}

As shown in Table 1, the soil surface layers at the three sites are characterized by a high proportion of sand. At each site, amendment led to changes in soil physico-chemical characteristics as shown by the increase in $\mathrm{pH}$, total $\mathrm{C}$ and total $\mathrm{N}$ contents, and CEC. Similarly, most metals showed higher values in the amended soils than in the control ones. The

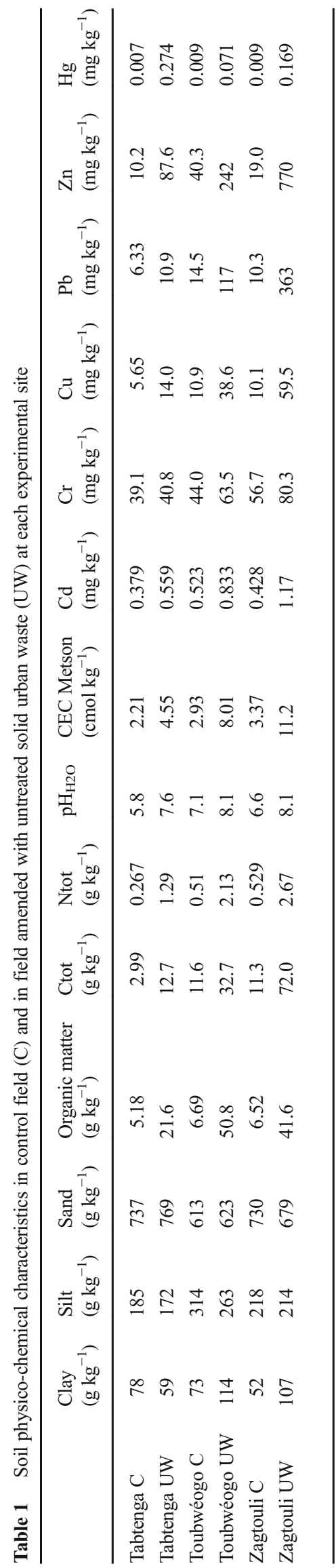


Zagtouli site experienced the highest impact as $\mathrm{Cd}, \mathrm{Zn}, \mathrm{Pb}$, and $\mathrm{Hg}$ were highly enriched in the amended field. On the contrary, the Tabtenga site experienced the least impact as only $\mathrm{Hg}$, and to a lesser extent, $\mathrm{Zn}$, and $\mathrm{Cd}$ were higher in the amended soils.

\section{Impact of amendment on TCH and sanitation indicators}

Data from the 2008 campaign showed a higher amount of TCH in the amended fields of Tabtenga and Toubwéogo than in the control ones, $p<0.001$ and $p<0.01$, respectively (Table 2). No significant differences were observed between the amended and control fields of Zagtouli. The higher amount of TCH in the amended field of Tabtenga was confirmed by the data from the 2011 campaign where the population of TCH was approximately seven times greater in amended fields.

Regarding sanitation indicators, coliforms, Staphylococci, and Enterococci were not isolated from any of the samples of the 2008 campaign whether they were collected in the amended or control fields.

To ensure that sanitation indicators were not misidentified, we selected several colonies per morphotype on the various selective media and identified them based on 16S rDNA sequencing (Table 3). On the TTC tergitol 7 medium (i.e., coliform detection), the yellow colonies and the red ones were all identified as belonging to Enterobacteriaceae. They were found to be closely related to Salmonella enterica, Pantoea stewartii, Shigella sonnei, or Cronobacter helveticus. The red colonies with a blue halo were found to be closely related to

Table 2 Bacterial counts for total culturable heterotrophs (TSA1/10 medium), sanitation indicators (TTC tergitol 7, Slanetz, and Chapman), and opportunistic pathogens (CAB, VIA, BCSA, and TB-T media) in agricultural soil samples collected at three sites in the periphery of Ouagadougou, Burkina Faso

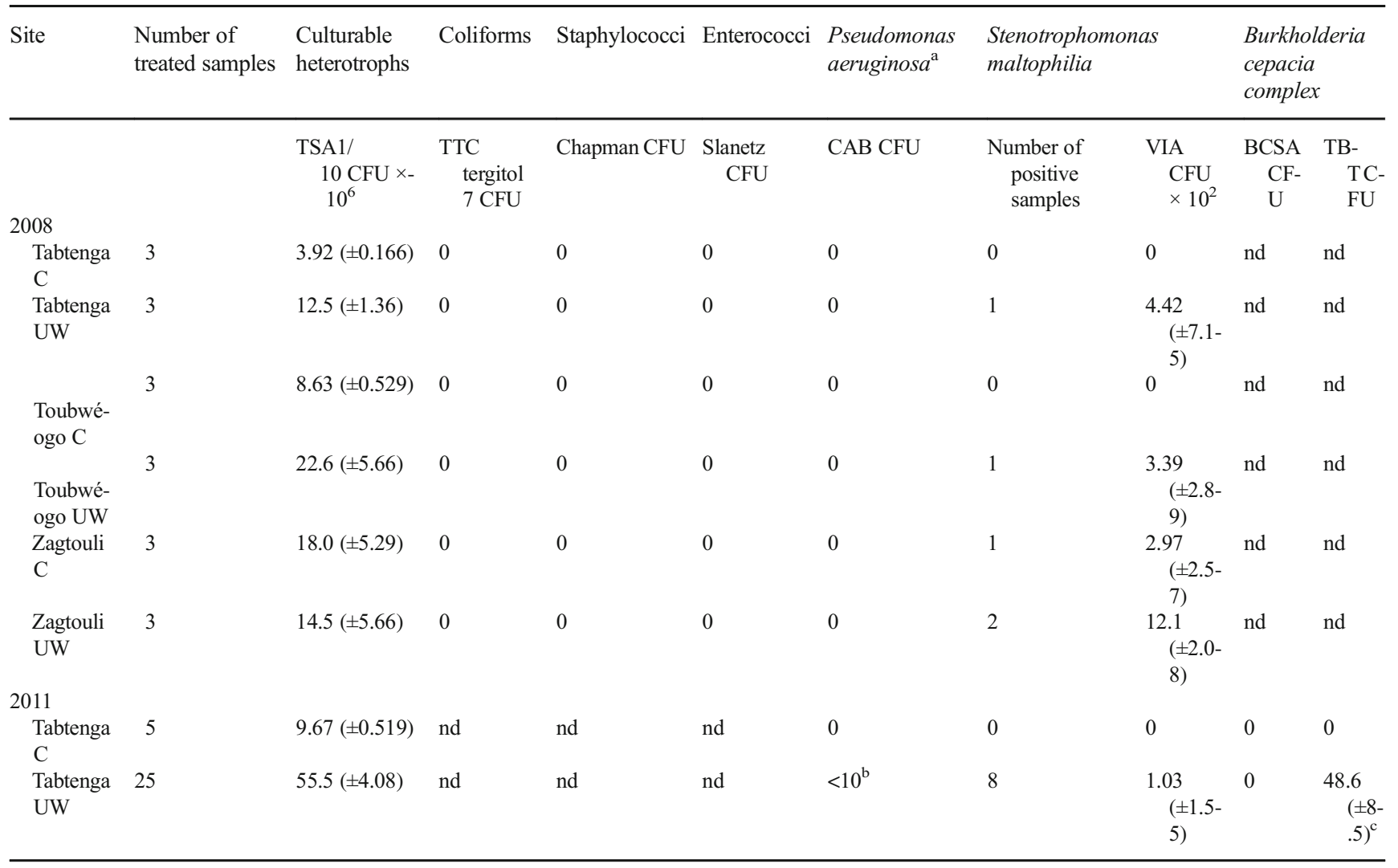

Two campaigns were performed in June 2008 and February 2011. At each site, soil samples were collected in unamended fields (C) and in fields amended with untreated solid urban waste (UW). Counts [colony forming units (CFU) per g drywt sample ( \pm standard deviation)] are either the mean of nine plates for the 2008 campaign or the mean of 75 plates and 15 plates for the amended fields and control ones, respectively, for the 2011 campaign. Standard errors are indicated in brackets

nd not done

${ }^{\text {a }}$ These data were partly reported in Deredjian et al. 2014

${ }^{\mathrm{b}} P$. aeruginosa was detected in one sample without the enrichment step and in seven samples after the enrichment step

${ }^{\mathrm{c}}$ Bcc was detected in 2 out of 25 samples using BCSA and in 10 out of 15 samples on CAB media after the enrichment step 
Table 3 16S rDNA-based identification of isolates growing on TTC tergitol 7 or Chapman media

\begin{tabular}{|c|c|c|c|c|}
\hline Isolate name & Medium & Size $(b p)^{a}$ & $\begin{array}{l}\text { Number of } \\
\text { isolates with } \\
\text { similar sequences }\end{array}$ & $\begin{array}{l}\text { Identification based on sequence producing significant } \\
\text { alignment with the maximum score (max identity); accession number }\end{array}$ \\
\hline 08BF03TD & TTC tergitol 7 & 1503 & 5 & Shigella sonnei $\mathrm{SsO} 46$ (98); NR_074894 \\
\hline 08BF07TK & TTC tergitol 7 & 1440 & 3 & Burkholderia phenoliruptrix BR3459a (99); NR_102849 \\
\hline 08BF11TN & TTC tergitol 7 & 1451 & 3 & Pantoea stewartii subp. Indologenes CIP104006 (98); NR_104928 \\
\hline 08BF19TK & TTC tergitol 7 & 1505 & 2 & Massilia albidiflava 45 (98); NR-043,308 \\
\hline 08BF31TG & TTC tergitol 7 & 1483 & 6 & Ralstonia mannitolilytica LMG6866 (99) ; NR_025385 \\
\hline 08BF31TL & TTC tergitol 7 & 1533 & 2 & Salmonella enterica subsp. Enterica serovar Typhi Ty2 (98); NR_074799 \\
\hline 08BF25TD & TTC tergitol 7 & 1493 & 14 & Cupriavidus plantarum ASC-64 (99); NR_109160 \\
\hline 08BF05TG & TTC tergitol 7 & 1412 & 3 & Cronobacter helveticus LMG23732 (99); NR_104980 \\
\hline 08BF01CA & Chapman & 1463 & 13 & Bacillus licheniformis DSM13 (99); NR_118996 \\
\hline 08BF03CD & Chapman & 1514 & 4 & Bacillus endophyticus 2DT (99); NR_025122 \\
\hline 08BF27CA & Chapman & 1433 & 8 & Bacillus aryabhattai B8W22 (100); NR_115953 \\
\hline 08BF15CA & Chapman & 1456 & 10 & Bacillus subtilis subsp. Subtilis OS-6.2 (99); NR_114996 \\
\hline 08BF29CG & Chapman & 1463 & 5 & Bacillus firmus NBRC 15306 (99); NR_112635 \\
\hline 08BF27CB & Chapman & 1439 & 11 & Bacillus cereus CM 2010 (99); NR_115714 \\
\hline
\end{tabular}

${ }^{\mathrm{a}}$ Length of the consensus sequence among isolates showing a similar sequence

species belonging to $\beta$-Proteobacteria, i.e., Cupriavidus plantarum, Massilia abidiflava, Ralstonia solanacearum, or Burkholderia phenoliruptrix. Fifty-one colonies selected on the Chapman media (i.e., Staphylococci detection) showed homology with Bacillus sequences such as Bacillus licheniformis, Bacillus endophyticus, Bacillus aryabhattai, Bacillus subtilis, Bacillus firmus or B. cereus. No colonies were observed on the Slanetz plates (i.e., Enterococci detection).

\section{Impact of amendment on opportunistic pathogens}

S. maltophilia was not detected in the control fields of Toubwéogo and Tabtenga in the 2008 samples. However, it was detected in the control field of Zagtouli and in the amended fields of all three sites. At each site, the highest values were detected in the amended fields. S. maltophilia was only detected in the amended field in the 2011 samples from Tabtenga. The numbers of $S$. maltophilia varied from $103( \pm 155)$ to $1210( \pm 208)$ CFU (g drywt soil) $)^{-1}$. The S. maltophilia population represented between $0.0002 \%$ (amended field of Tabtenga 2011) and $0.008 \%$ (amended field of Zagtouli 2008) of the total heterotrophs. It has to be noted that the number of $S$. maltophilia colonies on plates was always below ten and that variations were observed between samples from the same field, as some samples led to the detection of $S$. maltophilia whereas most of the others did not.

As reported earlier (Deredjian et al. 2014), no $P$. aeruginosa was detected in the control and amended soils from the 2008 campaign among all sites. None of the 30 samples from the 2011 sampling campaign at the Tabtenga site except one from the amended field site led to a direct isolation of $P$. aeruginosa. This sample was analyzed three times and either zero or one colony was obtained. The estimation of $P$. aeruginosa abundance was below $10 \mathrm{CFU} \mathrm{g}^{-1} \mathrm{dry}$ soil. The enrichment assays led to the detection of $P$. aeruginos $a$ in 7 out of 25 samples collected in the amended field.

Samples from the 2011 campaign were also analyzed for the presence of Bcc isolates because we reported that isolates closely related to Bcc were isolated on the CAB media from amended soil samples collected in 2008. Two different media were then used. Surprisingly, no Bcc isolate was obtained on the TB-T media. Only 2 out of 25 samples led to the detection of Bcc on the BCSA media whereas 10 out of 15 led to the detection on the $\mathrm{CAB}$ media after the enrichment step. Therefore, the estimated amount of Bcc in the amended field of Tabtenga was $48.6( \pm 8.5) \mathrm{CFU}$ (g drywt soil $)^{-1}$.

\section{Genetic diversity within $S$. Maltophilia, P. aeruginosa, and Bec}

Partial sequencing of gyrB showed that the $21 S$. maltophilia isolates recovered from the three sites in $2008(n=14)$ and from the Tabtenga site in $2011(n=7)$ belong to various clusters (Fig. 1). Strains from the 2008 campaign clustered either with the clinical strains K279, Ab5555, and DSM50170 or with the strain LMG11114. Each cluster contained isolates from two or three sites, suggesting the presence of a strain in several sites. None of the isolates from the 2011 campaign at the Tabtenga site clustered with K279a. Three of them, i.e., MEEB16, MEEB18, and MEEB20, were 


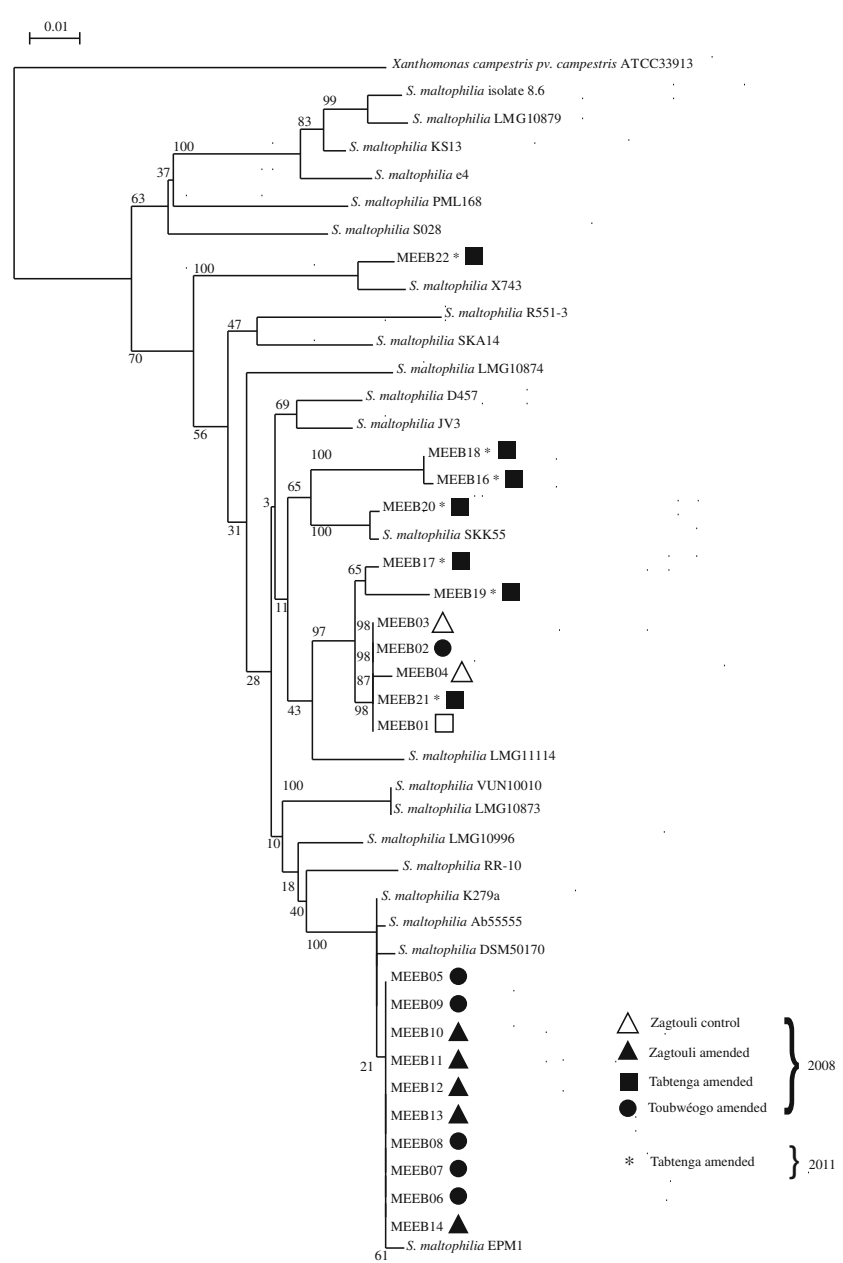

Fig. 1 Neighbor-joining tree based on partial gyr B gene sequences. Neighbor-joining tree of $21 \mathrm{~S}$. maltophilia isolates and international reference strains with xanthomonads used as outgroups

closely related to LMG11114. The others, i.e., strains MEEB17, MEEB19, and MEEB21 and strain MEEB22, were closely related either to SKK55 or to X743, respectively.

Sequencing of ecfX gene was performed to estimate the relation between the 38 isolates of $P$. aeruginosa recovered from the amended Tabtenga field (four isolates from the direct isolation and 34 from the enrichment procedure) with $P$. aeruginosa from other geographical regions and from clinical origin. Data showed that strains from Burkina Faso clustered in two major groups (Fig. 2). Nine isolates clustered between the outlier strain PA7 and all other Burkina Faso isolates and collection strains. Seventeen isolates shared the same sequence as EML1262 and clustered with most of the reference strains (PA01, PA1, PA96, YL84, LES431, DK2, c $7447 \mathrm{~m}$, SCV20265). The remaining isolates including EML1263, EML1264, and 11BFE3335 clustered with the other reference strains PA14, B136-33, MTB1, and NCGM2.S1. A previous study (Youenou et al. 2014) on the typing of $P$. aeruginosa isolates from soils including seven isolates from the present study (EML1258 to EML1264) had shown an important diversity despite the low number of isolates analyzed and their common soil origin (Tabtenga site) and that none of them had a multi-locus variable number tamdem repeat analysis (MLVA) profile similar to the other clinical and environmental strains studied.

Sequencing of the recA gene and phylogeny analysis showed that Bcc isolates from the Tabtenga site ( 22 from the CAB media in 2008 and two recovered from the BCSA media in 2011) were closely related to B. cenocepacia (two isolates), Burkholderia latens (one isolate), Burkholderia diffusa (one isolate), Burkholderia dolosa (17 isolates), and Burkholderia multivorans (three isolates) (Fig. 3). Clustering did not allow the differentiation of the isolates whether they were obtained from the $\mathrm{CAB}$ isolation procedure or the BCSA media and whether they were recovered from the 2008 or the 2011 campaigns.

\section{Antibiotic resistance properties of soil opportunistic pathogens}

Antimicrobial resistance properties of $38 P$. aeruginosa isolates, $21 \mathrm{~S}$. maltophilia isolates, and $24 \mathrm{Bcc}$ isolates were tested. Like the wild type (WT), we previously showed that all $P$. aeruginosa isolates $(100 \%)$ were resistant to minocycline and trimethoprim/sulfamethoxazole and sensitive to colistin, ciprofloxacin, isepamicin, amikacin, meropenem, aztreonam, cefepim, and ceftazidim (Youenou et al. 2014).

In the present study, we showed the isolates belonging to the Bcc have a profile similar to the wild type of B. cepacia. They were all resistant to ticarcilline, ticarcillin/clavulanic acid, quinolones and aminosides, imipenem, and colistin and sensitive to the other antibiotics.

All isolates of S. maltophilia from the 2008 campaign from both control and amended fields resist to at least ten antibiotics (Fig. 4) and were considered multi-resistant as they were able to resist to antibiotics belonging to at least three different classes. These resistances encompass penicillins, cephalosporins, monobactam, and carbapenems including meropenem, aminoglycosides, and polymixin. Some multi-drug resistant isolates showed increased resistances compared to strain K279a, the clinical antibiotic resistant reference strain, as they also showed resistance to fluoroquinolones. These multi-drug resistant isolates were detected at the three sites in amended and/or control fields. The genetic mechanisms underlying the resistance to these antibiotics was investigated for two of these isolates, i.e., strains MEEB01 and MEEB05 previously named BurA1 and BurE1, using comparative genomics and reported in Youenou et al. (2015). On the contrary, the isolates from the Tabtenga site sampled in 2011 showed differential susceptibilities with resistance to 3 to 13 antibiotics out of the 15 tested (Fig. 4). 
Fig. 2 Neighbor-joining tree based on total ecf $\mathrm{X}$ gene sequences from $38 P$. aeruginosa isolates from the 2011 campaign at the Tabtenga site and various $P$. aeruginosa reference strains. Asterisk indicates the sequence of four isolates obtained without an enrichment step
0.005

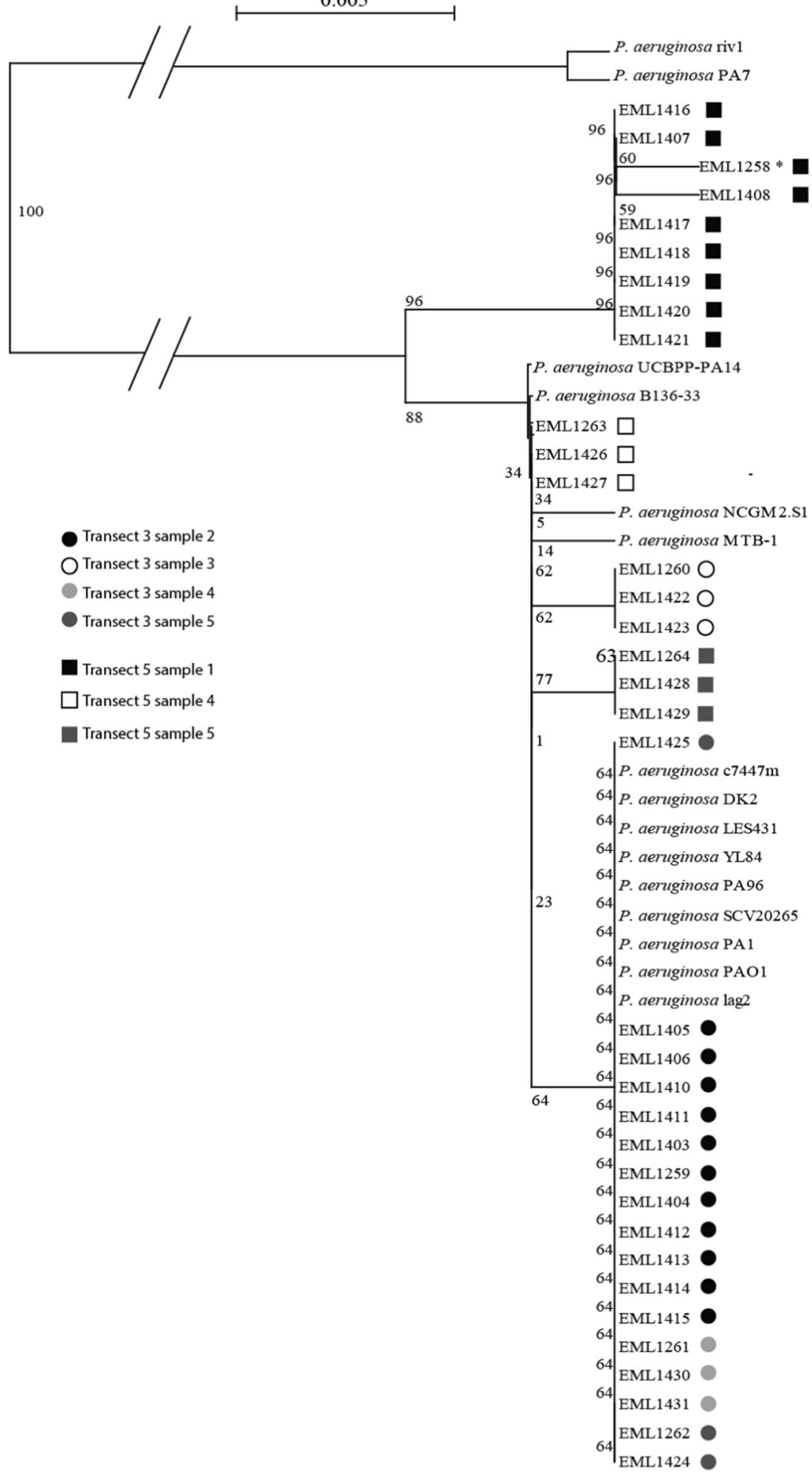

\section{Discussion}

Spreading of urban waste is widely used in African regions to increase soil fertility and therefore crop production. However, spreading without selection or pre-treatment could lead to important sanitary and environmental risks, as this practice is increasingly used in sub-urban agriculture to satisfy the food demand of a rising population. As shown at the three studied sites, this practice impacted the physico-chemical properties of soil. We observed that not only organic matter but also $\mathrm{pH}$ 
Fig. 3 Neighbor-joining tree based on partial recA gene sequences from $24 \mathrm{Bcc}$ isolates obtained from the Tabtenga site and various reference strains. Sequence from $B$. pseudomallei strain K96243 was used as the outgroup. All isolates were recovered from $\mathrm{CAB}$ (cetrimide agar base) plate after an acetamide enrichment step except two isolates (*) recovered on BCSA (Burkholderia cepacia selective agar) plate. ox indicates the two strains isolated from the 2008 sampling campaign

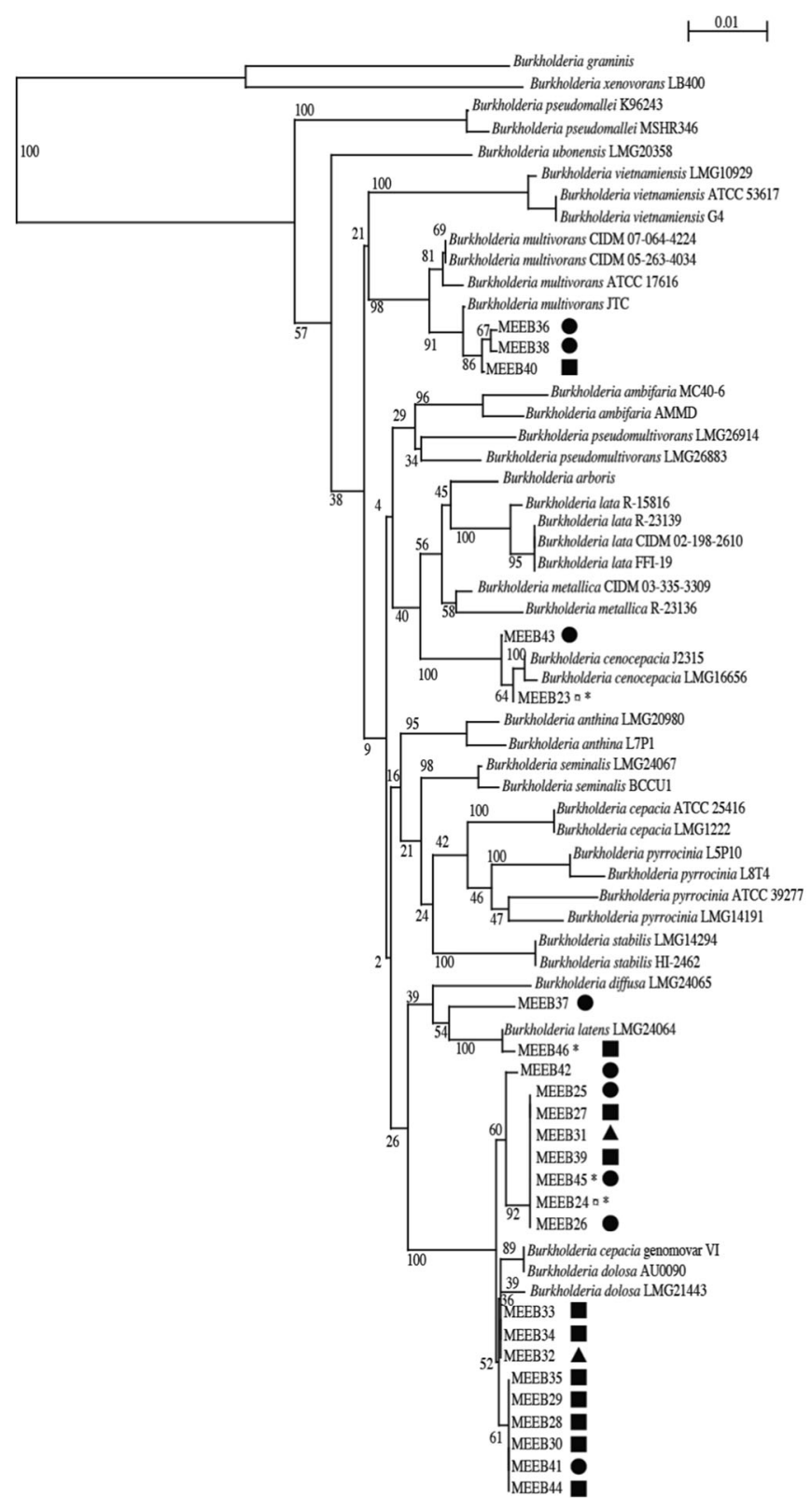

Transect 1

Transect 2 A Transect 3 and metal (mercury, zinc, lead, or cadmium) concentrations increased in amended fields. The heavy metals may be due to batteries, disposable household materials (i.e., bottle tops), and plastics in the untreated waste. The bioavailability of metals is known to be strongly influenced by $\mathrm{pH}$ and organic matter contents. Whether changes in these parameters affect microbial diversity and functions in these soils need to be investigated further.

Our data showed that amendment led to an increase in total culturable heterotrophs as well as an increase of bacteria able to grow on the various selective media used (data not shown). Similarly, at each site, the amount of opportunistic pathogens was higher in amended fields than in control ones. These observations are probably related to the repeated addition of organic matter over years. The addition of organic matter in agricultural soils represents a readily available source of energy, carbon, and nutrients for soil microorganisms. An increase in C-biomass and a stimulation of soil enzymatic activities have been reported (Albiach et al. 2000). Municipal solid waste-compost amendment generally increases the fungal and bacteria populations in amended soils (Crecchio et al. 2001; Debosz et al. 2002; Smith 2009). As soils from our study are very poor in organic matter, the addition of fresh organic material (vegetable residues) might be an easy-touse carbon source that enhances the level of heterotrophic bacteria (Bastida et al. 2008). Waste addition also led to an increase in crop production. Consequently, this plant effect might indirectly favor microbial growth including the opportunistic pathogens as these species, i.e., S. maltophilia and Bcc are well known as rhizospheric bacteria (Berg et al. 2005). 
Fig. 4 Antibiotic resistance of seven S. maltophilia isolates from the 2011 campaign and 14 $S$. maltophilia isolates from the 2008 sampling campaign. Brackets $=$ number of antibiotics

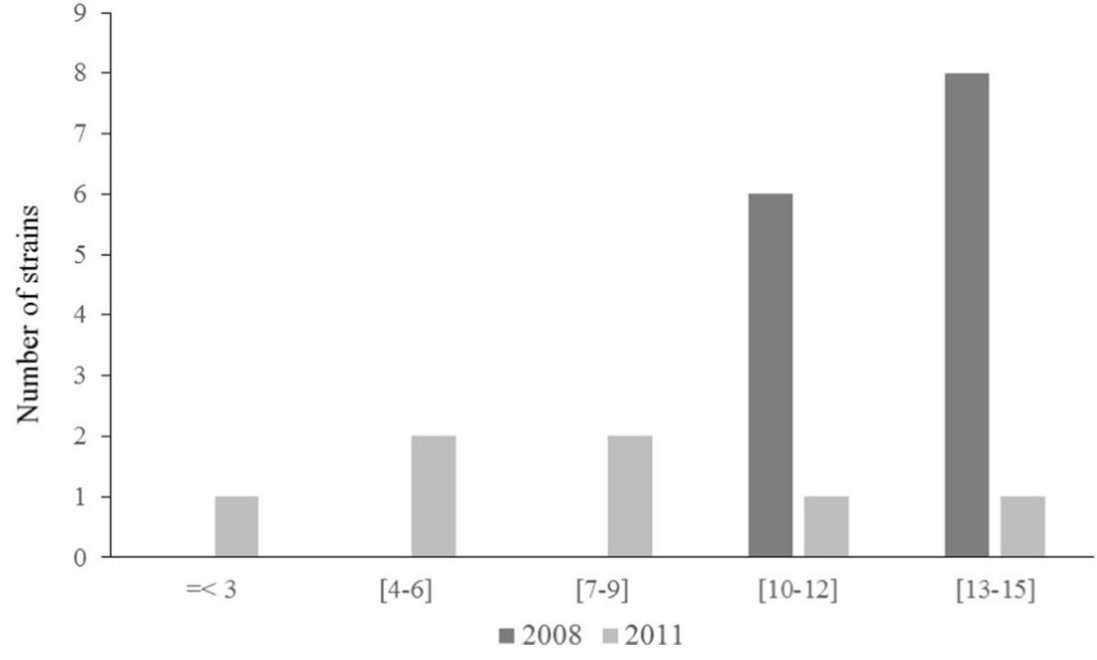

S. maltophilia has often been isolated from plants including rice (Hardoim et al. 2012), potato (Garbeva et al. 2001), and sweet flag (Marecik et al. 2008). The presence of Bcc in soil environments and especially in the rhizosphere of Graminae plants is well documented (i.e., Balandreau et al. 2001; Ramette et al. 2005; Dalmastri et al. 2007). The observed increase in heterotrophic bacteria and two out of the three opportunistic pathogen species, i.e., S. maltophilia and Bcc, can then be a consequence of the growth of indigenous soil populations. These pathogens might be present in the control soils but at a level below the detection limit of our methodologies. Amendment would favor their enrichment as it increased the amount of total heterotrophic bacteria. Our study focused on the bulk soil and showed that $S$. maltophilia and Bcc are able to survive in bulk soil despite the lack of plants and thus the low amount of nutrient supply. As these species are known to be abundant in the rhizosphere, it would then be interesting to evaluate how sorghum modifies the abundance and diversity of these species.

The increase in heterotrophs and pathogens could also be partly and/or temporarily due to the addition and growth of exogenous populations brought through amendment. As the waste used in the studied sites are of multiple origins, i.e., domestic, hospital (plasma pockets were seen during the time of sampling, Nazaret personal communication), and are not treated to eliminate pathogens, the latter could be disseminated in soils. Our data from the 2008 campaign showed the lack of detection of coliforms, Staphylococci, and Enterococci, suggesting that either these populations were absent from the initial waste, and/or that they do not persist at a detectable level using our methodology. We expected to detect some of these species given that untreated waste can contain potential pathogenic bacteria such as Salmonella or E. coli in a higher density than treated amendments, and fecal coliforms and streptococci, which indicate fecal contamination, frequently reach a density of $10^{7}-10^{8} \mathrm{CFU}$ (g drywt soil) ${ }^{-1}$ (around $10^{3}$ in treated composts) (Deportes et al. 1998; Hassen et al. 2001). However, it has to be noted that detection using the selective media used in this study was not as efficient as it could have been since several non-targeted species were able to grow and hampered the true estimation of the sanitary indicators.

Regarding opportunistic pathogens, P. aeruginosa is known to be present in animal- and human-originating waste (Lavenir et al. 2007; Deredjian et al. 2014). We were not able to detect $P$. aeruginosa following the 2008 campaign but we did detect that species in some samples from the 2011 campaign. This was probably due to the analysis of a greater number of samples (Deredjian et al. 2014). Also, its sporadic detection in the amended soil might be due to its presence in the urban waste. However, both our field campaigns were conducted during the high and dry seasons. As $P$. aeruginosa is known to prefer wet and humid conditions (Selezska et al. 2012; Deredjian et al. 2014), it would then be interesting to sample and analyze soil samples collected during the rainy season and also less distantly from the time of amendment spreading.

We analyzed the diversity among the various isolates from each pathogen species and compared them to reference strains from internal collections including clinical strains. Among $P$. aeruginosa isolates, we found two major groups with one group containing only strains from Burkina Faso. This observation suggested that the sub-Saharan soils harbor not only the common clones detected worldwide but also specific populations. Our previous study on the genetic typing of $P$. aeruginosa isolates using the MLVA approach showed on a subset of the isolate collection from Burkina Faso that intraspecies diversity exists at a low spatial scale (Youenou et al. 2014) and that these isolates do not share common profiles with all other included strains. A more discriminant method such as MLST should then be used to better relate these strains from Burkina Faso to the global $P$. aeruginosa population and evaluate whether some of the well-defined clones and clonal 
complexes (i.e., clone C, PA14, PA7) are present in African soils. The $\operatorname{gyr} B$ analysis revealed a low diversity among S. maltophilia isolates compared to what the literature reports from an epidemiological study. However, using a more discriminant genotyping method, i.e., pulse field gel electrophoresis (PFGE), we showed that most of the isolates from the 2008 campaign had a unique profile. The 14 isolates grouped in 11 PFGE profiles (data not shown) showing the high diversity within $S$. maltophilia populations recovered from a narrow geographical area. Interestingly, isolates of the same $\operatorname{gyr} B$ or PFGE genotypes were observed in the various sites, indicating the dissemination and/or the presence of common indigenous populations in various soils of the periphery of Ouagadougou. Regarding Bcc, the recA analysis showed that various species common among cystic fibrosis patients were present in the soils. B. cenocepacia genomovar IIIA-, B. dolosa-, and B. multivorans-like strains were identified. It has to be noted that few environmental isolates for these three species are available despite the fact that all these species have been frequently encountered among cystic fibrosis individuals and other clinical infections (Mahenthiralingam et al. 2000; Holden et al. 2009). To our knowledge, this is the first report of B. dolosa detection in soil. B. cenocepacia genomovar IIIA and B. multivorans were detected in the rhizosphere of maize in the USA (Ramette et al. 2005) as well as in the rhizosphere of maize and wheat in France and Australia (Balandreau et al. 2001). B. ambifaria-like strains were not detected in our soils despite their frequent detection and at a high level in the rhizosphere of various plants (Coenye et al. 2001; Dalmastri et al. 2007).

Urban waste may not only bring pathogens but also contaminants that could have selected for antibiotic resistance. For instance, contaminants such as the metals detected in the amended soils could favor the emergence of antibiotic resistance as these compounds could lead to both metal and antibiotic resistance (Baker-Austin et al. 2006). Our data on antibiotic resistance properties showed that our P. aeruginosa isolates had a wild phenotype suggesting that these isolates, whether they originated from waste or soils, were not exposed to a selective pressure favoring the development of resistance. Similarly, the Bcc isolates exhibited no additional resistance to the intrinsic ones these species might have. These observations would suggest that metals were not available in the soil or that their levels were not high enough to lead to antibiotic resistance. On the contrary, S. maltophilia isolates were mostly found to be resistant to several antibiotics. This observation did not come as a surprise as this species is characterized by a high level of intrinsic resistance to a variety of structurally unrelated antimicrobials (Sanchez et al. 2009) and is able to acquire new genes through gene transfer (Hu et al. 2011). Antibiotic hydrolysis or modification, target gene modification, membrane permeability alteration, and efflux pump overexpression are among the various mechanisms enabling
S. maltophilia to resist antimicrobials. Based on the literature, including our previous work, environmental isolates are reported to be as resistant as clinical ones (Berg et al. 1999; Deredjian et al. 2016) and to harbor as many resistance genes (Sanchez et al. 2009). The data from the present study therefore confirms these reports in terms of antibiotic resistance phenotypes. Similarly, whole genome sequencing of two strains recovered from the studied sites and comparative genomics confirmed that environmental strains have as many and diverse antibiotic resistant genes as clinical strains have (Youenou et al. 2015). Further studies are then needed to elucidate the origin of the multi-resistant phenotype and the role of environmental conditions in this multi-resistance selection.

In summary, spreading untreated urban waste on agricultural fields is a matter of great concern as it enhances both the amount of toxicants, i.e., metals, and directly or indirectly affects the amount of opportunistic pathogens closely related to the clones or clonal complexes involved in nosocomial- or community-acquired infections including multi-drug resistant isolates in soils. We could then strongly suggest performing an appropriate pre-treatment of these wastes before their use for agricultural practices. The pre-treatment should include separation of organic materials from others and be adapted for the reduction of both chemical and biological contaminants. While our study only focused on the selection pressure of metals, future studies should also include antimicrobials as we witnessed the presence of leftover pharmaceuticals and plasma packets in the amended fields during the various sampling campaigns.

Acknowledgments This work was supported by a CORUS project of the French "Ministère des Affaires Etrangères". B. Youenou was funded by a grant from the ADEME and the DGA. We thank the PARMIC technical platform and Rhône-Alpes Region Cluster "Environnement."

\section{References}

Adamek M, Overhage J, Bathe S, Winter J, Fischer R, Schwartz T (2011) Genotyping of environmental and clinical Stenotrophomonas maltophilia isolates and their pathogenic potential. PLoS One 6: e27615. doi:10.1371/journal.pone.0027615

Afon A (2007) An analysis of solid waste generation in a traditional African city: the example of Ogbomoso, Nigeria. Environ Urban 19:527-537

Albiach R, Canet R, Pomares F, Ingelmo F (2000) Microbial biomass content and enzymatic activities after the application of organic amendments to a horticultural soil. Bioresour Technol 75:43-48

Ali SW, Li R, Zhou WY, Sun JQ, Guo P, Ma JP, Li SP (2010) Isolation and characterization of an abamectin-degrading Burkholderia cepacia-like GB-01 strain. Biodegradation 21:441-452. doi:10.1007/s10532-009-9314-7

Alvarez-Ortega C, Wiegand I, Olivares J, Hancock RE, Martínez JL (2011) The intrinsic resistome of Pseudomonas aeruginosa to $\beta$ lactams. Virulence 2:144-146 
Baker-Austin C, Wright MS, Stepanauskas R, McArthur JV (2006) Coselection of antibiotic and metal resistance. Trends Microbiol 14: 176-182

Balandreau J, Viallard V, Cournoyer B, Coenye T, Laevens S, Vandamme P (2001) Burkholderia cepacia genomovar III is a common plantassociated bacterium. Appl Environ Microbiol 67:982-985

Baquero F, Martinez JL, Canton R (2008) Antibiotics and antibiotic resistance in water environments. Curr Opin Microbiol 19:260-265. doi:10.1016/j.copbio.2008.05.006

Bastida F, Kandeler E, Moreno JL, Ros M, García C, Hernández T (2008) Application of fresh and composted organic wastes modifies structure, size and activity of soil microbial community under semiarid climate. Appl Soil Ecol 40:318-329

Berg G, Roskot N, Smalla K (1999) Genotypic and phenotypic relationships between clinical and environmental isolates of Stenotrophomonas maltophilia. J Clin Microbiol 37:3594-3600

Berg G, Eberl L, Hartmann A (2005) The rhizosphere as a reservoir for opportunistic human pathogenic bacteria. Environ Microbiol 7: 1673-1685

Canton R, Morosini MI (2011) Emergence and spread of antibiotic resistance following exposure to antibiotics. FEMS Microbiol Reviews 35:977-991. doi:10.1111/j.1574-6976.2011.00295.x

Coenye T, Mahenthiralingam E, Henry D, LiPuma JJ, Laevens S, Gillis M, Speert DP, Vandamme P (2001) Burkholderia ambifaria sp. nov., anovel member of the Burkholderia cepacia complex including biocontrol and cystic fibrosis-related isolates. Int J Syst Evol Microbiol 51:1481-1490

Colinon C, Deredjian A, Hien E, Brothier E, Bouziri L, Cournoyer B, Hartman A, Henry S, Jolivet C, Ranjard L, Nazaret S (2013) Detection and enumeration of Pseudomonas aeruginosa in soil and manure assessed by an ecfX qPCR assay. J Appl Microbiol 114:1734-1749. doi:10.1111/jam.12189

Crecchio C, Curci M, Mininni R, Ricciuti P, Ruggiero P (2001) Shortterm effects of municipal solid waste compost amendments on soil carbon and nitrogen content, some enzyme activities and genetic diversity. Biol Fertil Soils 34:311-318

Dalmastri C, Baldwin A, Tabacchioni S, Bevivino A, Mahenthiralingam E, Chiarini L, Dowson C (2007) Investigating Burkholderia cepacia complex populations recovered from Italian maize rhizosphere by multilocus sequence typing. Environ Microbiol 9:1632-1639

Debosz K, Petersen SO, Kure LK, Ambus P (2002) Evaluating effects of sewage sludge and household compost on soil physical, chemical and microbiological properties. Appl Soil Ecol 19:237-248

Deportes I, Benoit-Guyod JL, Zmirou D, Bouvier MC (1998) Microbial disinfection capacity of municipal solid waste (MSW) composting. J Appl Microbiol 85:238-246

Deredjian A, Colinon C, Hien E, Brothier E, Youenou B, Cournoyer B, Dequiedt S, Hartmann A, Jolivet C, Houot S, Ranjard L, Saby NPA, Nazaret S (2014) Low occurrence of Pseudomonas aeruginosa in agricultural soils with and without organic amendment. Front Cell Inf Microbiol 4:53. doi:10.3389/fcimb.2014.00053

Deredjian A, Alliot N, Blanchard L, Brothier E, Anane M, Cambier P, Jolivet C, Khelil MN, Nazaret S, Saby N, Thioulouse J, Favre-Bonté S (2016) Occurrence of Stenotrophomonas maltophilia in agricultural soils and antibiotic resistance properties. Res Microbiol 167: 313-324. doi:10.1016/j.resmic.2016.01.001

Eaton D, Hilhorst T (2003) Opportunities for managing solid waste flows in the peri-urban interface of Bamako and Ouagadougou. Environ Urban 15:53-63

Edgar RC (2004) MUSCLE: multiple sequence alignment with high accuracy and high throughput. Nuc Ac Res 32:1792-1797

Edrington TS, Fox WE, Callaway TR, Anderson RC, Hoffman DW, Nisbet DJ (2009) Pathogen prevalence and influence of composted dairy manure application on antimicrobial resistance profiles of commensal soil bacteria. Foodborne Pathog Dis 6:217-224. doi:10.1089/fpd.2008.0184
FAO-IUSS-ISRIC (2006) World reference base for soil resources. A framework for international classification, correlation and communication. World Soil Resources Reports 103, Rome, p. 128

Farzan A, Friendship RM, Cook A, Pollari F (2010) Occurrence of Salmonella, Campylobacter, Yersinia enterocolitica, Escherichia coli $\mathrm{O} 157$ and Listeria monocytogenes in swine. Zoonoses Public Health 57:388-396. doi:10.1111/j.18632378.2009.01248

Garbeva P, van Overbeek LS, van Vuurde JWL, van Elsas JD (2001) Analysis of endophytic bacterial communities of potato by plating and denaturing gradient gel electrophoresis (DGGE) of 16S rDNA based PCR fragments. Microb Ecol 41:369-383

Garrec N, Picard-Bonnaud F, Pourcher AM (2003) Occurrence of Listeria sp and $L$. monocytogenes in sewage sludge used for land application: effect of dewatering, liming and storage in tank on survival of Listeria species. FEMS Immunol Med Microbiol 35:275-283

Gouy M, Guindon S, Gascuel O (2010) SeaView version 4: a multiplatform graphical user interface for sequence alignment and phylogenetic tree building. Mol Biol Evol 27:221-224. doi:10.1093 /molbev/msp259

Green SK, Schroth MN, Cho JJ, Kominos SK, Vitanza-Jack VB (1974) Agricultural plants and soil as a reservoir for Pseudomonas aeruginosa. Appl Microbiol 28:987-991

Hagedorn C, Gould WD, Bardinelli TR, Gustavson DR (1987) A selective medium for enumeration and recovery of Pseudomonas cepacia biotypes from soil. Appl Environ Microbiol 53:2265-2268

Hardoim PR, Hardoim CC, van Overbeek LS, van Elsas JD (2012) Dynamics of seed-borne rice endophytes on early plant growth stages. PLoS One 7:e30438. doi:10.1371/journal.pone.0030438

Hassen A, Belguith K, Jedidi N, Cherif A, Cherif M, Boudabous A (2001) Microbial characterization during composting of municipal solid waste. Bioresour Technol 80:217-225

Henry DA, Campbell ME, Lipuma JJ, Speert DP (1997) Identification of Burkholderia cepacia isolates from patients with cystic fibrosis and use of a simple new selective medium. J Clin Microbiol 35:614-619

Hickey WJ, Focht DD (1990) Degradation of mono-, di-, and trihalogenated benzoic acids by Pseudomonas aeruginosa JB2. Appl Environ Microbiol 56:3842-3850

Holden MT, Seth-Smith HM, Crossman LC, Sebaihia M, Bentley SD, Cerdeño-Tárraga AM, Thomson NR, Bason N, Quail MA, Sharp S, Cherevach I, Churcher C, Goodhead I, Hauser H, Holroyd N, Mungall K, Scott P, Walker D, White B, Rose H, Iversen P, MilHomens D, Rocha EP, Fialho AM, Baldwin A, Dowson C, Barrell BG, Govan JR, Vandamme P, Hart CA, Mahenthiralingam E, Parkhill J (2009) The genome of Burkholderia cenocepacia J2315, an epidemic pathogen of cystic fibrosis patients. J Bacteriol 191: 261-277. doi:10.1128/JB.01230-08

Hu LF, Chang X, Ye Y, Wang ZX, Shao YB, Shi W, Li X, Li JB (2011) Stenotrophomonas maltophilia resistance to thrimethroprim/ sulfamethoxazole mediated by acquisition of sul and $d f \mathrm{r}$. genes in a plasmid-mediated class 1 integron. Int J Antimicrob Agents 37: 230-234. doi:10.1016/j.ijantimicag.2010.10.025

Jechalke S, Heuer H, Siemens J, Amelung W, Smalla K (2014) Fate and effects of veterinary antibiotics in soil. Trends Microbiol 22:536 545. doi:10.1016/j.tim.2014.05.005

Kaboré TWT, Houot S, Hien E, Zombre P, Hien V, Masse D (2010) Effect of the raw materials and mixing ratio of composted wastes on the dynamic of organic matter stabilization and nitrogen availability in composts of sub-Saharan Africa. Bioresour Technol 101:1002-1013

Kaszab E, Szoboszlay S, Dobolyi C, Háhn J, Pék N, Kriszt B (2011) Antibiotic resistance profiles and virulence markers of Pseudomonas aeruginosa strains isolated from composts. Bioresour Technol 102:1543-1548. doi:10.1016/j. biortech.2010.08.027

Kuske CR, Barns SM, Grow CC, Merrill L, Dunbar J (2006) Environmental survey for four pathogenic bacteria and closely 
related species using phylogenetic and functional genes. J Forensic Sci 51:548-558

Lavenir R, Jocktane D, Laurent F, Nazaret S, Cournoyer B (2007) Improved reliability of Pseudomonas aeruginosa PCR detection by the use of the species-specific ecf $X$ gene target. J Microbiol Methods 70:20-29

Lee DY, Lauder H, Cruwys H, Falletta P, Beaudette LA (2008) Development and application of an oligonucleotide microarray and real-time quantitative PCR for detection of wastewater bacterial pathogens. Sci Total Environ 398:203-211. doi:10.1016/j. scitotenv.2008.03.004

Livermore DM (2012) Fourteen years in resistance. Intern J Antimicrob Agents 39:283-294. doi:10.1016/j.ijantimicag.2011.12.012

Mahenthiralingam E, Bischof J, Byrne SK, Radomski C, Davies JE, AvGay VP (2000) DNA-based diagnostic approaches for identification of Burkholderia cepacia complex, Burkholderia vietnamiensis, Burkholderia multivorans, Burkholderia stabilis, and Burkholderia cepacia genomovars I and III. J Clin Microbiol 38:3165-3173

Marecik R, Króliczak P, Czaczyk K, Białas W, Olejnik A, Cyplik P (2008) Atrazine degradation by aerobic microorganisms isolated from the rhizosphere of sweet flag (Acorus calamus L.). Biodegradation 19:293-301

Mendes R, Garbeva P, Raaijmakers JM (2013) The rhizosphere microbiome: significance of plant beneficial, plant pathogenic, and human pathogenic microorganisms. FEMS Microbiol Rev 37:634663. doi:10.1111/1574-6976.12028

Meng J, Doyle MP (1997) Emerging issues in microbiological food safety. Annu Rev Nutr 17:255-275

Pinot C, Deredjian A, Nazaret S, Brothier E, Cournoyer B, Segonds C, Favre-Bonté S (2011) Identification of Stenotrophomonas maltophilia strains isolated from environmental and clinical samples: a rapid and efficient procedure. J Appl Microbiol 111:11851193. doi:10.1111/j.1365-2672.2011.05120

Pitcher DG, Saunders NA, Owen RJ (1989) Rapid extraction of bacterial genomic DNA with guanidium thiocyanate. Lett Appl Microbiol 8: $151-156$

Ramette A, LiPuma JJ, Tiedje JM (2005) Species abundance and diversity of Burkholderia cepacia complex in the environment. Appl Environ Microbiol 71:1193-1201

Sanchez MB, Hernandez A, Martinez JL (2009) Stenotrophomonas maltophilia drug resistance. Future Microbiol 4:655-660. doi: $10.2217 / \mathrm{fmb} .09 .45$

Selezska K, Kazmierczak M, Müsken M, Garbe J, Schobert M, Häussler S, Wiehlmann L, Rohde C, Sikorski J (2012) Pseudomonas aeruginosa population structure revisited under environmental focus: impact of water quality and phage pressure. Environ Microbiol 14:1952-1967. doi:10.1111/j.1462-2920.2012.02719

Semenov AV, van Overbeek L, van Bruggen AH (2009) Percolation and survival of Escherichia coli $\mathrm{O} 157: \mathrm{H} 7$ and Salmonella enterica serovar Typhimurium in soil amended with contaminated dairy manure or slurry. Appl Environ Microbiol 75:3206-3215. doi:10.1128 /AEM.01791-08
Singh RP, Singh P, Ibrahim MH, Hashim R (2011) Land application of sewage sludge: physicochemical and microbial response. Rev Environ Contam Toxicol 214:41-61. doi:10.1007/978-1-46140668-6

Smith SR (2009) A critical review of the bioavailability and impacts of heavy metals in municipal solid waste composts compared to sewage sludge. Environ Int 35:142-156. doi:10.1016/j. envint.2008.06.009

Su JQ, Wei B, Ou-Yang WY, Huang FY, Zhao Y, HJ X, Zhu YG (2015) Antibiotic resistome and its association with bacterial communities during sewage sludge composting. Environ Sci Technol 49:73567363. doi: $10.1021 /$ acs.est.5b01012

Talavera G, Castresana J (2007) Improvement of phylogenies after removing divergent and ambiguously aligned blocks from protein sequence alignments. Syst Biol 56:564-577

Trung TT, Hetzer A, Göhler A, Topfstedt E, Wuthiekanun V, Limmathurotsakul D, Peacock SJ, Steinmetz I (2011) Highly sensitive direct detection and quantification of Burkholderia pseudomallei bacteria in environmental soil samples by using realtime PCR. Appl Environ Microbiol 77:6486-6494. doi:10.1128 /AEM.00735-11

Vedler E, Vahter M, Heinaru A (2004) The completely sequenced plasmid pEST4011 contains a novel IncP1 backbone and a catabolic transposon harboring $t f d$ genes for 2,4-dichlorophenoxyacetic acid degradation. J Bacteriol 186:7161-7174

Weisburg WG, Barns SM, Pelletier DA, Lane DJ (1991) 16S ribosomal DNA amplification for phylogenetic study. J Bacteriol 173:697-703

Whitman WB, Coleman DC, Wiebe WJ (1998) Prokaryotes: the unseen majority. Proc Natl Acad Sci U S A 95:6578-6583

Yamamoto S, Harayama S (1998) Phylogenetic relationships of Pseudomonas putida strains deduced from the nucleotide sequences of gyr B, rpoD and 16S rRNA genes. Int J Syst Bacteriol 48:813819

Youenou B, Brothier E, Nazaret S (2014) Diversity among strains of Pseudomonas aeruginosa from manure and soil, evaluated by multiple locus variable number tandem repeat analysis and antibiotic resistance profiles. Res Microbiol 165:2-13. doi:10.1016/j. resmic.2013.10.004

Youenou B, Favre-Bonté S, Bodilis J, Brothier E, Dubost A, Muller D, Nazaret $S$ (2015) Comparative genomics of environmental and clinical Stenotrophomonas maltophilia strains with different antibiotic resistance profiles. Genome Biol Evol 7:2484-2505. doi:10.1093 /gbe/evv161

Young JS, Gormley E, Wellington EM (2005) Molecular detection of Mycobacterium bovis and Mycobacterium bovis BCG (Pasteur) in soil. Appl Environ Microbiol 71:1946-1952

Zhu YG, Johnson TA, Su JQ, Qiao M, Guo GX, Stedtfeld RD, Hashsham SA, Tiedje JM (2013) Diverse and abundant antibiotic resistance genes in Chinese swine farms. Proc Natl Acad Sci U S A 110: 3435-3440. doi:10.1073/pnas. 1222743110 